\title{
OPORTUNIDADES POLÍTICAS EM UM PRESIDENCIALISMO DE COALIZÃO
}

\author{
Matheus Mazzilli Pereira \\ é doutor em Sociologia pela Universidade Federal do Rio Grande do Sul (UFRGS). Porto Alegre, RS, \\ Brasil. E-mail<matheus.mazzilli@gmail.com> \\ Orcid: 0000-0003-2817-0856 \\ http://dx.doi.org/10.1590/0102-217252/105
}

\section{Introdução}

Ao longo da década de 1990, o movimento brasileiro de gays, lésbicas, bissexuais, travestis e transsexuais (LGBT) foi um importante ator a influenciar o desenho de políticas públicas na área da saúde e do combate à epidemia de HIV/Aids no Brasil (Facchini, 2003; Grangeiro, Silva e Teixeira, 2009; Ramos, 2004). Na década seguinte, com a chegada do Partido dos Trabalhadores (PT) à Presidência da República, em 2003, esse movimento passou a conquistar vitórias no que tange ao desenvolvimento de políticas públicas especificamente voltadas aos direitos sexuais, nas quais temas relacionados à sexualidade foram vistos de forma "não mais vinculada necessariamente a considerações relativas à saúde" (Carrara, 2010, p. 135). Nesse período, o movimento LGBT passou a defender como uma de suas principais demandas o combate à homofobia, apresentando propostas como a criminalização e a prevenção da violência homofóbica (Fernandes, 2012; Ramos e Carrara, 2006).

A trajetória das conquistas desse movimento ao longo dos governos federais do PT, porém, foi pouco regular. Durante os primeiros anos, foram realizadas diversas ações que atenderam a demandas de seus ativistas (Carrara, 2010; Facchini, 2009; Ramos e Carrara, 2006). Pesquisadoras indicam, no entanto, que tais ações foram pouco efetivadas ao longo 
desses anos, não tendo se tornado políticas públicas institucionalizadas com dotação orçamentária regular (Froemming, Irineu e Navas, 2010; Irineu, 2014; Mello, Avelar e Maroja, 2012). Pesquisadoras, sugerem, ainda, que, no decorrer dos governos federais do PT, ocorreu uma gradativa diminuição no reconhecimento público da chefia do Executivo em relação às demandas desse movimento. $\mathrm{O}$ veto à distribuição do kit anti-homofobia desenvolvido pelo Ministério da Educação (MEC) e a declaração da presidenta Dilma Rousseff (PT) de que seu governo não faria "propaganda de opção sexual" são vistos como exemplos desse processo (Aguião, Vianna e Gutterres, 2014; Machado e Rodrigues, 2015).

Como é possível que um mesmo movimento conquiste resultados políticos favoráveis às suas demandas em interações com um governo e, ao interagir com um governo do mesmo partido em um momento posterior, não obtenha mais tal sucesso? Nos diversos modelos teóricos desenvolvidos por 218 pesquisadores de movimentos sociais para a análise de seus resultados políticos, "estruturas de mobilização", "opinião pública" e "oportunidades políticas" são apontados como elementos explicativos centrais (Carlos, Dowbor e Albuquerque, 2016; Giugni, 1998). Este artigo tem como foco a mudança nas oportunidades políticas para o movimento LGBT.

Por um lado, parte da literatura destaca que mudanças partidárias e ideológicas na chefia do Executivo têm forte impacto sobre a abertura e o fechamento de oportunidades para movimentos sociais. Por outro, pesquisadoras têm destacado a importância das redes que inserem ativistas de movimentos sociais em subsistemas de políticas públicas. $\mathrm{O}$ caso em análise desafia ambas as perspectivas. Nele, o mesmo partido permaneceu na chefia do Executivo Federal ao longo do período em que oportunidades se abriram e se fecharam para o movimento LGBT, ainda que com mudanças na presidência. A troca de comando entre o presidente Lula e a presidenta Dilma gerou mudanças ideológicas no 
perfil da presidência que, no entanto, são menores se comparadas a uma possível mudança de partido. Nesse período, foram também mantidos (e até mesmo ampliados) os espaços de participação institucional desse movimento no governo, assim como suas redes com a burocracia estatal.

Para explicar esse fenômeno, neste artigo proponho como hipótese que, devido ao desenho institucional brasileiro, marcado por um "presidencialismo de coalizão" (Abranches, 1988), o fechamento e a abertura de oportunidades políticas para movimentos sociais no Brasil são influenciados pelo gerenciamento que governos fazem sobre sua heterogeneidade. De forma mais específica, tal processo é influenciado pelas formas como governos constroem coalizões com partidos e atores heterogêneos e gerenciam a influência que tais atores têm sobre as políticas públicas por eles desenvolvidas. No caso em análise, sugiro que, pela análise do crescimento da influência do conservadorismo religioso nas coalizões dos governos do PT entre 2003 e 2014, torna-se possível compreender o fechamento de oportunidades para o movimento LGBT.

A divisão do artigo é apresentada a seguir. Na primeira seção, reviso a literatura sobre movimentos sociais, seus resultados e oportunidades políticas. Desenvolvo, ainda, o argumento teórico principal deste trabalho. A seção seguinte trata dos dados e métodos utilizados na pesquisa empírica que dá base a este artigo. Apresento, na sequência, os resultados a respeito do combate à homofobia nos governos federais do PT. Em seguida, mostro dados que indicam importantes mudanças nas coalizões desses governos para, depois, apresentar minhas considerações finais.

\section{Movimentos sociais, oportunidades políticas e resultados políticos}

Movimentos sociais podem obter resultados múltiplos, em aspectos culturais, econômicos e biográficos da vida 
social (Giugni, McAdam e Tilly, 1999). Também podem ter resultados políticos significativos. Podem afetar, por exemplo, as políticas públicas desenvolvidas pelos governos e as leis propostas e aprovadas pelos parlamentares. Seus membros podem ter seus direitos reconhecidos e passar a ser incluídos como categorias importantes a serem ouvidas em processos de participação popular (Amenta e Young, 1999). Este artigo tem como foco esse último tipo de resultado dos movimentos sociais. Os modelos teóricos desenvolvidos para explicar os resultados políticos de movimentos sociais, em geral, articulam três variáveis centrais: as estruturas de mobilização de recursos, a opinião pública e as oportunidades políticas (Carlos, Dowbor e Albuquerque, 2016; Giugni, 1998). O presente trabalho foca a última dessas variáveis.

Oportunidades políticas são definidas pela literatura como "dimensões consistentes - mas não necessariamente formais ou permanentes - do ambiente político que forne220 cem incentivos para a ação coletiva ao afetarem as expectativas das pessoas quanto ao sucesso e ao fracasso" (Tarrow, 2009, p. 105). Esse conceito apresenta uma definição ampla, tendo sido utilizado de formas distintas por diversos autores. Nas palavras de Gamson e Meyer (1996, p. 275, tradução livre), ele corre o risco de se tornar algo como "uma esponja que suga todos os aspectos relativos ao ambiente dos movimentos sociais". Pesquisadores propõem diferentes definições sobre quais aspectos da mobilização coletiva são afetados pelas oportunidades políticas, sobre quem exatamente é afetado por elas, sobre por quais mecanismos as oportunidades afetam os movimentos e sobre quais são os aspectos específicos do contexto político que influenciam ativistas (Meyer e Minkoff, 2004). O conceito de "oportunidades políticas", portanto, apenas se revela útil na medida em que trabalhos empíricos indiquem quais dimensões do contexto político-institucional afetam quais aspectos da mobilização coletiva. Neste artigo, busco investigar quais aspectos específicos do 
contexto político incidem sobre as oportunidades para que movimentos sociais obtenham resultados políticos positivos. Nas subseções seguintes, organizo o debate em torno desse tema em dois grandes modelos: um centrado no perfil ideológico-partidário da chefia do Executivo e outro centrado nas disputas entre burocratas, que ocorrem dentro dos subsistemas de políticas públicas.

\section{Governos e partidos}

O conceito de "oportunidades políticas" tem como principal contribuição a ideia de que Estados podem agir de diferentes formas em relação a movimentos sociais e a outros aspectos relevantes para eles, afetando a emergência, o desenvolvimento e os resultados da mobilização coletiva. Estados podem fornecer maior ou menor acesso à participação institucional a diferentes grupos sociais e facilitar ou reprimir as atividades de movimentos sociais (McAdam, 1996; Tarrow, 2009). Podem ser compostos por um número maior ou menor de aliados dos ativistas (McAdam, 1996; Tarrow, 2009; Van Dyke, 2003). Podem, ainda, promover mudanças em áreas de políticas públicas relevantes para os movimentos (Amenta, Caren e Stobaugh, 2012; Meyer, 1993a) e mudar sua retórica e seu posicionamento público a respeito dessas políticas (Meyer, 1993a). Podem, por fim, ser formados por elites mais ou menos divididas em relação a essas medidas (McAdam, 1996; Tarrow, 2009). Boa parte da literatura que utiliza esse conceito associa a ocorrência de mudanças nessas ações a transformações em três níveis: nos regimes políticos; nos alinhamentos políticos e eleitorais; e, por fim, nas tendências eleitorais e na ideologia dos governos.

No primeiro desses casos, características mais permanentes dos desenhos institucionais afetam a tendência dos governos a se comportarem de certa maneira frente à contestação política. Diferentes desenhos constitucionais criam diferentes obstáculos e incentivos para a mobilização 
coletiva (Meyer, 1993b), gerando regimes mais ou menos abertos, democráticos e centralizadores cujas características são apenas modificadas por intensos processos de ruptura (Almeida, 2003; Amenta, Caren e Stobaugh, 2012; Tilly, 1997).

No segundo desses níveis, no interior de regimes, partidos políticos mudam suas estratégias eleitorais e formam novos alinhamentos, o que influencia suas ações enquanto governo ou oposição (McAdam, 1986; Tarrow, 2009). No caso do movimento pelos direitos civis dos Estados Unidos, por exemplo, fluxos migratórios modificaram a importância estratégica do eleitorado negro para os partidos políticos. Essa modificação provocou uma mudança na estratégia eleitoral dos partidos Democrata e Republicano, realinhando suas posições em relação às políticas raciais e abrindo oportunidades para o movimento negro dos Estados Unidos (McAdam, 1986).

No terceiro nível, observa-se que governos e partidos progressistas e conservadores tendem a agir de formas distintas em relação a movimentos sociais específicos e que a substituição de governos de esquerda por governos de direita (ou vice-versa) ou a mudança em tendências eleitorais de médio prazo tendem a mudar as formas pelas quais os Estados interagem com cada movimento social (Amenta, Caren e Stobaugh, 2012; McAdam e Tarrow, 2011; Meyer, 1993a). Pesquisadores que analisaram experiências de participação política institucional na década de 1990 no Brasil utilizaram esse tipo de argumento. De acordo com as investigações desses autores, o surgimento, a continuidade e a efetividade de mecanismos de participação política estavam ligados à presença de partidos de esquerda na chefia do Executivo municipal. Ações da chefia do Executivo seriam essenciais para gerar uma sensação de confiança junto a organizações da sociedade civil, assim estimulando sua 
participação (Abers, 1998; Avritzer, 2003; Lüchmann, 2002; Silva, 2003; Teixeira, 2003; Wampler, 2003).

Nesses três níveis, o que gera a abertura e o fechamento de oportunidades para movimentos sociais é aquilo que a chefia dos governos faz ou deixa de fazer, seja ela influenciada por regimes políticos, por estratégias eleitorais ou por seu perfil ideológico-partidário. Esse modelo apresenta forças e fraquezas para a compreensão da abertura e do fechamento de oportunidades políticas no caso brasileiro. A força desse modelo reside em destacar a importância das decisões tomadas pela chefia do Executivo, indicando, assim, que movimentos sociais são profundamente impactados por processos eleitorais. Já sua fraqueza consiste em criar a imagem de um governo demasiadamente homogêneo, superestimando a agência da chefia do Executivo em relação aos seus subsistemas. A construção teórica de um governo homogêneo tendeu, ainda, a criar uma divisão rígida entre a política institucional e extrainstitucional, entre os membros do governo e os ativistas outsiders, ignorando, desta forma, a possibilidade de ocorrência de interpenetração entre Estado e sociedade (Goldstone, 2003; Pettinicchio, 2012). É justamente a partir das críticas à ideia de um Estado homogêneo e de uma separação entre Estado e sociedade civil que a outra perspectiva de análise da abertura e do fechamento de oportunidades políticas aqui apresentada foi construída.

\section{Burocracias e subsistemas}

Outra parte da literatura sobre movimentos sociais e seus resultados políticos tem destacado o impacto das dinâmicas internas a órgãos governamentais para explicar a abertura e o fechamento de oportunidades políticas ${ }^{1}$. Nessa perspectiva, as mudanças na chefia do governo não são totalmente

\footnotetext{
${ }^{1}$ Isso ocorre de forma indireta, já que o conceito de "oportunidades" é raramente utilizado nesses estudos.
} 
desconsideradas. Porém a agência da chefia dos governos se resume, em grande parte das análises, ao estímulo à entrada de burocratas que compartilham seus projetos na estrutura do governo. De acordo com essas análises, portanto, a abertura de oportunidades para movimentos sociais é resultado direto da agência desses burocratas e ativistas e apenas indireto da agência da chefia do governo. A literatura brasileira tem se destacado na formulação dessa perspectiva.

Empiricamente, a literatura nacional foi instigada pelas mudanças provocadas pela entrada do PT no Governo Federal, processo que gerou maior diálogo entre alguns movimentos sociais e o governo na formação de algumas políticas públicas. Analisando esse contexto, pesquisadoras de movimentos sociais no Brasil criticaram os pressupostos da externalidade e da confrontação, presentes em parte da literatura sobre movimentos sociais, que defendiam que movimentos eram (ou deveriam ser) atores completamente 224 independentes dos governos e que adotam uma postura de confronto em relação a eles, relacionando toda forma de institucionalização à perda de autonomia e à cooptação (Abers e Von Büllow, 2011; Silva, 2015; Tatagiba, 2010).

Criticando tais pressupostos, estas autoras destacaram que ativistas não resumem sua ação a táticas extrainstitucionais de confronto, mas também, porventura, apostam em táticas institucionais (Abers, Serafim e Tatagiba, 2014; Albuquerque, 2015; Banaszak, 2005; Carlos, 2015; Katzenstein, 1990; Pettinicchio, 2012; Silva e Oliveira, 2011; Silva, 2015). Pessoas com vínculos fortes ou apenas indiretos com organizações de movimentos sociais podem, por exemplo, utilizar a tática de ocupação de cargos (Abers, 2015; Silva e Oliveira, 2011; Silva, 2015; Tatagiba e Teixeira, 2016), tornando-se "burocratas ativistas", pessoas que se aproximam de governos "a ponto de ir trabalhar neles, com intuito específico de promover ações em benefício de causas pelas quais militam" (Ferreira e Lotta, 2016, p. 15). 
Burocratas ativistas se inserem em diferentes órgãos governamentais que integram diferentes "subsistemas de políticas públicas". Neles, passam a fazer parte de "coalizões de defesa", grupos que buscam traduzir seus valores em políticas públicas em um confronto constante com adversários internos (Sabatier e Weible, 2007). Suas possibilidades de ação nesse confronto estão, em grande medida, delimitadas pelas características e trajetórias institucionais do subsistema ao qual estão integrados (Abers, Serafim e Tatagiba, 2014; Schmitt e Silva, 2016).

Assim, movimentos sociais interagem, na maior parte das vezes, com partes mais específicas do Estado do que a chefia do Executivo, sendo o Estado um espaço heterogêneo cujas partes têm características e trajetórias distintas que configuram oportunidades ou ameaças para os movimentos sociais (Abers, Serafim e Tatagiba, 2014; Carlos, Dowbor e Albuquerque, 2016). Nesse sentido, Carlos, Dowbor e Albuquerque (2016) defendem que para entender os efeitos de movimentos sociais sobre políticas públicas

É imprescindível que a descrição das instituições do Estado visadas pela ação do movimento faça parte da análise. Aqui estamos para além das características gerais do sistema político tal como posto pelo conceito de oportunidades, e nos aproximamos das instituições particulares com seus legados e burocracias (Carlos, Dowbor e Albuquerque, 2016 p. 14).

Nesse modelo, portanto, a mudança nas oportunidades e ameaças para movimentos sociais é decorrente de dinâmicas internas aos subsistemas de políticas públicas. A força desse modelo reside justamente nas fraquezas do modelo anterior. Essa literatura indica que o Estado é profundamente heterogêneo e que as trajetórias e confrontos institucionais importam. $\mathrm{O}$ ponto fraco desse modelo está justamente nos pontos fortes do modelo anterior. Essa literatura tem reduzido a ação do Poder Executivo ao aumento ou à diminuição da permeabilidade dos 
subsistemas, ignorando que as dinâmicas internas a eles são influenciadas por decisões da chefia do governo de maneiras diversas e constantes. Na próxima seção, proponho um modelo que busca conciliar a análise dos governos e dos partidos que os compõem à análise das burocracias e dos subsistemas.

\section{Heterogeneidade gerenciada e presidencialismo de coalizão}

Proponho como hipótese neste artigo que a abertura e o fechamento de oportunidades para movimentos sociais não podem ser compreendidas nem pela ideia de um governo homogêneo que age sobre subsistemas praticamente passivos, nem pela ideia do governo como um conjunto de instituições com características quase autônomas. Governos são heterogeneidades gerenciadas. É, portanto, no processo de gerenciamento da heterogeneidade interna dos governos que ocorrem mudanças que abrem e fecham oportunidades para movimentos sociais específicos em interação com governos.

Governos são heterogeneidades gerenciadas em dois sentidos. Em um primeiro, que pode ser depreendido da literatura revisada, destaca-se que quando um partido político assume a chefia do Executivo, busca transformar suas preferências em políticas públicas. Porém a chefia do Executivo age em um território já "desenhado", na medida em que suas instituições têm uma longa trajetória e são atravessadas por lógicas e confrontos políticos próprios. A chefia do Executivo age sobre seus ministérios e secretarias buscando interferir em seus confrontos internos, não só indicando pessoal aliado em cargos de confiança, mas também ajudando a moldar seu orçamento e sinalizando prioridades. Nesse sentido, oportunidades se abrem e se fecham para movimentos sociais de acordo com a forma como os partidos na chefia do Executivo buscam gerenciar os confrontos e lógicas dos subsistemas de políticas públicas para garantir que as coalizões de defesa que tenham valores próximos aos seus se consagrem vencedores, 
o que nem sempre é possível. Esse processo complexo não será analisado em detalhes neste artigo.

O que analisarei aqui é o segundo sentido pelo qual governos são heterogeneidades gerenciadas em casos como o brasileiro. Com isso, busco explicitar outras motivações para a interferência da chefia do Poder Executivo sobre seus ministérios e secretarias que não suas preferências ideológico-partidárias. Essa segunda heterogeneidade tem origem no desenho do sistema político brasileiro, que pode ser caracterizado como um "presidencialismo de coalizão". Tal desenho institucional impõe ao partido que chefia o Executivo a criação de grandes coalizões com partidos heterogêneos do ponto de vista ideológico para a obtenção de vantagens eleitorais e maioria no Congresso Nacional (Abranches, 1988; Cheibub, Przeworski e Saiegh, 2002) .

A formação de coalizões de governo no Brasil, em geral, garante ao Poder Executivo um alto índice de aprovação das medidas por ele propostas (Figueiredo e Limongi, 2000), mas também implica um custo para a chefia do Executivo. Estudos recentes têm demonstrado que, ao se juntar a coalizões governamentais, partidos não buscam apenas cargos, mas também uma influência efetiva sobre as políticas públicas. Por exemplo, embora a maior parte dos projetos aprovados pelo Congresso Nacional tenha origem no Executivo (Figueiredo e Limongi, 2001), tais projetos são intensamente modificados pelos membros da coalizão governamental em sua tramitação (Freitas, 2016) e as políticas públicas deles resultantes são fortemente controladas por esses atores (Araújo, 2016). Assim, no caso brasileiro, "a agenda do Executivo não é a agenda do presidente, mas sim a agenda da coalizão" (Freitas, 2016, p. 111).

No que se refere ao debate proposto neste artigo, a literatura sobre presidencialismo de coalizão no Brasil mostra que, ao gerenciar seus subsistemas de políticas públicas, o partido que chefia o Executivo não busca apenas traduzir os seus valores em políticas públicas. Para garantir a fidelidade de sua 
coalizão de governo, a chefia do Executivo também deve ceder vitórias a aliados ideologicamente heterogêneos e, assim, transformar alguns de seus valores em políticas públicas. Para complexificar ainda mais esse quadro, coalizões governamentais não reúnem apenas partidos políticos no Brasil. No Congresso Nacional, formam-se grupos suprapartidários de parlamentares que têm convicções semelhantes acerca de temas específicos, as frentes parlamentares (Coradini, 2010). Na medida em que atravessam partidos políticos e a divisão entre governo e oposição, tais frentes parlamentares agem também dentro das coalizões de governo, impondo mais um conjunto de interesses a ser gerenciado pelos governos.

A partir desses argumentos, sugiro que, devido ao desenho brasileiro, oportunidades políticas se abrem e se fecham no Brasil por meio do gerenciamento que a chefia do Executivo faz de sua dupla heterogeneidade, ou seja, do gerenciamento feito sobre seus subsistemas heterogêneos 228 de forma a manter a fidelidade de sua coalizão de governo também heterogênea. Nesse artigo, buscarei demonstrar que as variações nos resultados políticos conquistados pelo movimento LGBT foram simultâneas ao crescimento da influência da Frente Parlamentar Evangélica (FPE) ${ }^{2}$ nas coalizões de governo do PT. Minha hipótese para explicar essa variação concomitante sugere que, para atender aos interesses de sua coalizão e manter a sua fidelidade, a chefia do Executivo diminuiu o poder de ação dos defensores de políticas de combate à homofobia dentro dos seus subsistemas, fechando as oportunidades para o movimento LGBT.

\footnotetext{
2 A FPE foi fundada no ano de 2003, ainda que informalmente. Esse grupo é formado, majoritariamente, por membros de partidos de centro e de direita, mas se distribuem de forma equilibrada entre governo e oposição (Silva, 2012; Trevisan, 2013). A FPE não abriga todos os opositores do movimento LGBT no Congresso e, logo, parte dessa oposição está excluída da análise. Ainda, não busco afirmar que todos os fiéis e líderes políticos de igrejas evangélicas são contrários ao movimento LGBT.
} 


\section{Dados e métodos}

Este trabalho faz parte de uma pesquisa mais ampla em desenvolvimento no âmbito do curso de doutoramento em sociologia de seu autor, cuja fase de produção de dados ocorreu entre os anos de 2016 e 2017. Aqui apresento apenas os dados de sua primeira etapa, que buscou mapear mudanças: a) nos resultados políticos obtidos pelo movimento LGBT junto ao Governo Federal entre 2003 e 2014; b) e mudanças nas coalizões de governo nesse mesmo período, focando a FPE. Esses dados são limitados, na medida em que podem apenas identificar a concorrência de fenômenos, sem identificar uma conexão causal entre eles. Uma fase qualitativa de pesquisa foi realizada, mas dados dessa fase ainda não estão presentes neste trabalho.

No que tange aos resultados políticos do movimento LGBT, dois conjuntos de dados são mobilizados. O primeiro deles foi reunido em uma linha do tempo de iniciativas do Governo Federal direcionadas de forma específica a pessoas LGBT entre 2003 e 2014. Essa linha do tempo reúne apenas iniciativas exclusivamente relacionadas a pessoas LGBT, excluindo iniciativas mais gerais ou de outras áreas, como a aprovação do Programa Nacional de Direitos Humanos $3(2009)^{3}$. Foram consultadas três fontes para a construção dessa linha do tempo: a) os levantamentos prévios realizados pelo Grupo Ser-Tão ${ }^{4}$ e por Aguião (2014) ; b) os sites da Secretaria de Direitos Humanos (SDH), da Secretaria de Políticas para Mulheres da Presidência da República (SPM), da Secretaria de Educação Continuada, Alfabetização, Diversidade e Inclusão do MEC e o portal de Saúde LGBT do Ministério da Saúde (MS); e c) dezessete entrevistas com

\footnotetext{
3 Duas exceções foram adotadas para esse critério. A primeira é o curso "Gênero e Diversidade na Escola", que contou com a participação direta de pesquisadores da área de gênero e sexualidade em sua formação. A segunda é a criação de um grupo de trabalho para desenvolvimento de propostas de combate ao racismo, sexismo e lesbofobia na SPM.

4 Relatório de pesquisa disponível em: <http://www.sertao.ufg.br/politicaslgbt/ interna.php?id=1->. Acesso em: fev. 2018.
} 
ativistas do movimento LGBT e com burocratas da SDH, MEC, MS, Ministério da Cultura (MinC) e Ministério da Justiça.

O segundo conjunto de dados relacionados aos resultados políticos do movimento LGBT reúne informações sobre recursos destinados pelo Governo Federal a ações voltadas a organizações e pessoas LGBT no período de abrangência da pesquisa. Para realizar esse levantamento, foram utilizadas informações sobre transferências de recursos federais disponibilizados pelo Portal da Transparência do Governo Federal para o período entre 2004 e 2014 (dados de 2003 não estão disponíveis). Foram realizados dois tipos de levantamento. O primeiro levantamento buscou mapear recursos transferidos por meio de qualquer ação governamental para as organizações filiadas à Associação Brasileira de Lésbicas, Gays, Bissexuais, Travestis e Transexuais (ABGLT) $)^{5}$. O segundo levantamento buscou mapear recursos de ações do Governo Federal voltadas 230 de forma específica a pessoas LGBT transferidos para qualquer entidade (sociedade civil, estados e municípios) ${ }^{6}$.

Já no que se refere às mudanças nas coalizões de governo, esse trabalho foca apenas a Câmara dos Deputados. Três dimensões foram analisadas: a) o peso numérico da FPE nas coalizões; b) o poder posicional dos membros dessa frente dentro do Congresso Nacional; c) e o controle do governo sobre a sua coalizão. Fazem parte de uma coalizão de governo aqueles partidos que possuem membros chefiando ministérios ou secretarias com status ministerial em decorrência de acordos

\footnotetext{
5 Para essa busca, é necessário identificar o CNPJ de cada organização. Das 222 organizações listadas no site da ABGLT em outubro de 2016 (incluindo a própria ABGLT), foi encontrado o CNPJ de 198 organizações. As organizações não encontradas não possuem CNPJ, ou a informação não foi encontrada pelo pesquisador. O CNPJ de cada empresa foi confirmado com dados do site da Receita Federal.

${ }^{6}$ Para identificar tais ações, foi realizada uma busca por palavras-chave ("homofobia", "gay", "diversidade", "gênero", "preconceito", "discriminação", "orientação", "centro de referência”) nos Planos Plurianuais (PPA) e nas Leis Orçamentárias Anuais (LOA) apresentadas no período de abrangência da pesquisa.
} 
políticos com o partido da presidenta. Coalizões de governo começam e terminam, portanto, em três casos: com a mudança da composição partidária dos gabinetes; com a mudança na chefia do Executivo; ou com a realização de novas eleições (Figueiredo, 2012). De acordo com o Centro Brasileiro de Análise e Planejamento (CEBRAP), as coalizões dos governos analisados estão distribuídas conforme o Quadro 1.

\section{Quadro 1}

Coalizões de governo no segundo Governo Lula e no primeiro Governo Dilma

\begin{tabular}{|l|c|c|}
\hline Gabinete & \multicolumn{1}{|c|}{ Partidos } & Duração \\
\hline Lula 2A & PT - PR - PCdoB - PSB - PTB - PMDB - PP - PRB & Jan. 2007 - Mar. 2007 \\
\hline Lula 2B & PT - PR - PCdoB - PSB - PTB - PMDB - PP - PDT - PRB & Abr. 2007 - Mar. 2010 \\
\hline Lula 2C & PT - PR - PCdoB - PSB - PMDB - PP - PDT - PRB & Abr. 2010 - Dez. 2010 \\
\hline Dilma 1A & PT - PR - PCdoB - PSB - PMDB - PDT - PP & Jan. 2011 - Fev. 2012 \\
\hline Dilma 1B & PT - PR - PCdoB - PSB - PMDB - PDT - PP - PRB & Mar. 2012 - Set. 2013 \\
\hline Dilma 1C & PT - PR - PCdoB - PMDB - PDT - PP - PRB & Out. 2013 - Dez. 2014 \\
\hline
\end{tabular}

Fonte: CEBRAP.

Para mapear o peso numérico de membros da FPE nas coalizões de governo, deputados evangélicos foram identificados pelos relatórios produzidos pelo Departamento Intersindical de Assessoria Parlamentar (DIAP) intitulados "Radiografia do Novo Congresso". Tais relatórios foram revisados com informações do Portal da Câmara dos Deputados referentes a filiação partidária e à presença nas legislaturas analisadas. O DIAP define como membros da FPE, "além de bispos e pastores, aquele parlamentar que professa a fé segundo a doutrina evangélica” (DIAP, 2006, p. 33) ${ }^{7}$.

7 A lista nominal completa dos deputados identificados pelo DIAP como membros da bancada evangélica é apenas disponibilizada no relatório referente ao primeiro Governo Dilma Rousseff (DIAP, 2010, pp. 44-45). Porém, comparando-se o número de parlamentares reeleitos de acordo com esse relatório com o número de parlamentares citado no relatório anterior, inferiu-se que todos os parlamentares evangélicos da legislatura entre 2007 e 2010 foram reeleitos. A eles, foi adicionado o deputado André Zacharow (PMDB), erroneamente listado como "novo" no relatório referente ao primeiro Governo Dilma de acordo com dados do Portal da Câmara dos Deputados. Assim, foi possível reconstruir a lista dos 33 deputados da bancada evangélica para os anos entre 2007 e 2010. 
Com relação ao poder da FPE no Congresso Nacional, foi criada uma escala de poder posicional de deputados da FPE em políticas públicas voltadas à população LGBT. Nessa escala, cada deputado recebeu um escore de influência para cada governo. Tal escore é formado por indicadores de ocupação de posições dentro da Câmara dos Deputados que ampliam a influência e o poder de barganha dos deputados evangélicos sobre esse tema ${ }^{8}$. Foram atribuídos pontos para cada congressista que ocupou alguma dessas posições em qualquer momento e durante qualquer período de tempo nos governos analisados. Os dados para a construção dessa escala foram obtidos no Portal da Câmara dos Deputados. A escala foi construída a partir dos critérios informados no Quadro 2.

Por fim, para a terceira subdimensão da análise das mudanças nas coalizões de governo, o controle da chefia do Executivo sobre sua coalizão, foram usados dados do Basômetro desenvolvido pelo grupo Estadão. Esse banco de dados for232 nece informações acerca da porcentagem de deputados que votaram de acordo com a orientação do governo na Câmara dos Deputados. São incluídas todas as votações nominais e excluídos os casos em que o governo não deu orientação de voto aos deputados. Os dados utilizados por essa ferramenta on-line têm origem no Portal da Câmara dos Deputados ${ }^{9}$.

\footnotetext{
8 Os critérios para a definição de tais espaços foram estabelecidos a partir da realização de onze entrevistas com assessoras e deputadas ligadas à FPE e à Frente Parlamentar de Defesa da Cidadania LGBT.

9 A fidelidade de deputados membros das coalizões de governo em votações nominais em plenário não é suficiente para analisar a complexidade do gerenciamento de coalizões, excluindo, por exemplo, negociações que impedem que projetos cheguem ao plenário (Hiroi e Rennó, 2014). Tal indicador, porém, se refere a um aspecto central da formação de coalizões, a garantia de aprovação de projetos em plenário, e, logo, se mostra suficiente para os objetivos desta pesquisa.
} 


\section{Quadro 2 \\ Escala de poder posicional dos parlamentares sobre políticas públicas voltadas à população LGBT}

\begin{tabular}{|c|c|c|}
\hline Cargo & Ponderação & Justificativa \\
\hline $\begin{array}{l}\text { Mesa Diretora da Câmara } \\
\text { dos Deputados (presidente, } \\
\text { secretário, tesoureiro etc., } \\
\text { excluindo-se suplentes). }\end{array}$ & $x 4$ & $\begin{array}{l}\text { Confere acesso direto à agenda do plenário } \\
\text { Câmara dos Deputados, e, assim, influên- } \\
\text { cia sobre quais projetos serão votados em } \\
\text { plenário e sobre o ritmo das votações. A } \\
\text { mesa diretora é, ainda, a responsável pela } \\
\text { aprovação final do orçamento público. }\end{array}$ \\
\hline $\begin{array}{l}\text { Líder de partido, líder de } \\
\text { bloco partidário ou líder da } \\
\text { maioria ou minoria. }\end{array}$ & x3 & $\begin{array}{l}\text { Líderes de partido e de blocos partidários } \\
\text { são responsáveis por indicar a posição da } \\
\text { bancada em votações em plenário. Exer- } \\
\text { cem, ainda, influência sobre as comissões } \\
\text { legislativas (Müller, 2005): definem a dis- } \\
\text { tribuição das presidências no Colégio de } \\
\text { Líderes, indicam membros dos partidos } \\
\text { para compor as comissões e podem par- } \\
\text { ticipar das comissões mesmo não sendo } \\
\text { membros delas (sem direito ao voto). } \\
\text { Já líderes da maioria e da minoria podem } \\
\text { participar de qualquer comissão (sem di- } \\
\text { reito a voto quando não forem membros } \\
\text { delas) e orientar o voto da maioria e da } \\
\text { minoria no plenário. }\end{array}$ \\
\hline $\begin{array}{l}\text { Mesa Diretora das Comissões*: } \\
\text { - Comissão de Direitos } \\
\text { Humanos e Minorias (CDHM). } \\
\text { - Comissão de Legislação } \\
\text { Participativa (CLP). } \\
\text { - Comissão de Seguridade } \\
\text { Social e Família (CSSF). } \\
\text { - Comissão de Educação (CE). } \\
\text { - Comissão de Cultura } \\
\text { (CCULT). } \\
\text { - Comissão de Constituição e } \\
\text { Justiça (CCJ). } \\
\text { - Comissão de Finanças e } \\
\text { Tributação (CFT). }\end{array}$ & $\times 2$ & $\begin{array}{l}\text { O pertencimento à mesa diretora de uma } \\
\text { comissão dá ao parlamentar acesso à } \\
\text { agenda dessa comissão, dando a ele poder } \\
\text { de influir sobre qual projeto será votado e } \\
\text { em qual ritmo, bem como sobre a defini- } \\
\text { ção de sua relatoria. Confere também visi- } \\
\text { bilidade pública aos parlamentares. } \\
\text { Entrevistadas e entrevistados indicaram } \\
\text { a CDHM, a CLP, a CSSF, a CE e a CCULT } \\
\text { como especialmente relevantes para dis- } \\
\text { putas em torno de questões LGBT. Indi- } \\
\text { caram, ainda, que a CCJ (na qual devem } \\
\text { tramitar todas as proposições) e a CFT (na } \\
\text { qual devem tramitar proposições que en- } \\
\text { volvem questões financeiras e orçamentá- } \\
\text { rias) são relevantes para todas as disputas } \\
\text { que ocorrem no Congresso Nacional. }\end{array}$ \\
\hline $\begin{array}{l}\text { Membro titular ou suplente } \\
\text { das comissões acima citadas. }\end{array}$ & $x 1$ & $\begin{array}{l}\text { Membros titulares ou suplentes das comis- } \\
\text { sões legislativas têm direito a voto nas ma- } \\
\text { térias que tramitam nessa comissão. Devido } \\
\text { à flexibilidade de trocas entre membros titu- } \\
\text { lares e suplentes, ambos são relevantes nas } \\
\text { disputas internas às comissões. }\end{array}$ \\
\hline
\end{tabular}

Fonte: autoria própria.

\footnotetext{
* Na medida em que a Comissão de Educação e Cultura foi dividida no período referente ao primeiro mandato da presidenta Dilma Rousseff, para que o número de indicadores se mantivesse estável, as duas comissões foram tratadas como uma para a construção dos escores referentes a esse período. Dessa forma, a ocupação de cargos simultâneos na CE e na CCULT não conferiram pontuação dupla ao congressista.
} 


\section{Combate à homofobia nos Governos Federais do PT (2003-2014)}

Ao longo dos governos federais do PT aqui analisados, o movimento LGBT obteve uma série de resultados políticos positivos, porém de forma pouco regular. A Figura 1 mostra a linha do tempo de iniciativas governamentais voltadas à população LGBT entre os anos de 2003 e $2014^{10}$. No primeiro Governo Lula, observa-se um número pequeno de iniciativas governamentais voltadas exclusivamente a pessoas LGBT, o que, provavelmente, pode ser explicado pelo estágio inicial de desenvolvimento dessas iniciativas. Nesse período, no entanto, foi elaborado o programa "Brasil sem Homofobia" (BSH), que balizou e justificou muitas das iniciativas subsequentes.

O número de iniciativas cresceu significativamente no segundo Governo Lula, no qual as principais demandas do movimento LGBT foram atendidas. Nesse governo, foi construído aquilo que a ABGLT denominou de "tripé da cidada234 nia” das políticas públicas para pessoas LGBT: a realização de uma conferência em 2008, a elaboração de um plano de políticas públicas em 2009 e a criação de um conselho em 2010. Cursos de formação de professores e profissionais da segurança pública começaram a ser ofertados nesses anos e instruções normativas relacionadas ao nome social, ao processo transexualizador e aos direitos de casais do mesmo sexo editadas.

\footnotetext{
${ }^{10}$ Para a lista completa das iniciativas que formam essa linha do tempo, consultar o autor.
} 


\section{Figura 1}

\section{Linha do Tempo de Iniciativas do Poder Executivo Federal direcionadas a pessoas LGBT (2004-2014)}

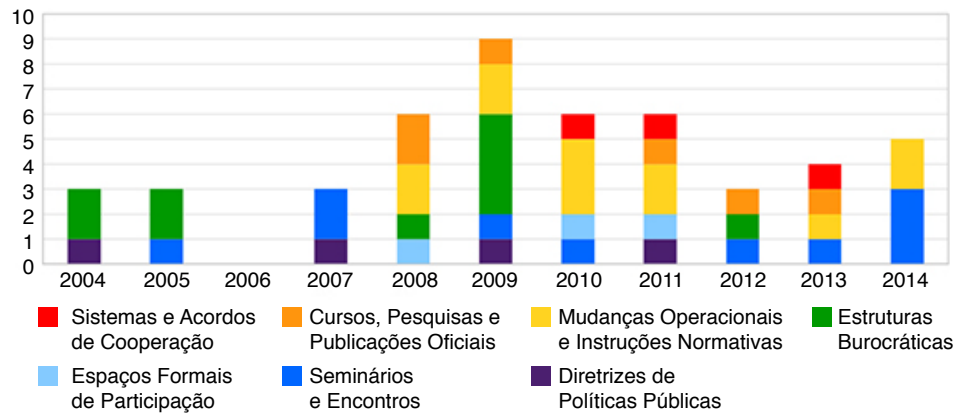

Fonte: autoria própria, com dados de pesquisa empírica, Grupo Ser-Tão ${ }^{11}$ e Aguião (2014).

No início do primeiro Governo Dilma, o ano de 2011 também foi marcado por um número alto de iniciativas, tais como a segunda edição da Conferência Nacional LGBT e a primeira edição do Relatório de Violência Homofóbica no Brasil, que deixou de ser publicado a partir de 2013. A partir de 2012, porém, observa-se uma diminuição nesse número, excetuando-se encontros e seminários, em geral, relacionados ao tema da saúde, ao qual o movimento buscou não se limitar a partir do primeiro Governo Lula, objetivando a ampliação do reconhecimento de suas demandas.

Muitas das iniciativas que integram a Figura 1, no entanto, dependiam de investimentos para que efetivamente produzissem resultados positivos para a população LGBT. Exemplos desse tipo são programas de políticas públicas como o programa BSH. Integrando-se os dados que mapeiam investimentos realizados pelo Governo Federal através de organizações filiadas à ABGLT aos dados que mapeiam investimentos realizados por ações governamentais

\footnotetext{
11 Relatório de pesquisa disponível em: <www.sertao.ufg.br/politicaslgbt/interna. php?id=1>. Acesso em: fev. 2018.
} 
específicas para pessoas LGBT, é possível observar a seguinte variação nesses investimentos.

Ocorreu um forte crescimento desses investimentos entre 2006 e 2007. Tais investimentos se estabilizaram em um patamar médio entre 2008 e 2009 e foram ampliados em 2010. Entre 2011 e 2013, ocorreu um forte decréscimo nesses investimentos seguido de um aumento em 2014 por meio de ações da SDH e do MS, atingindo-se níveis semelhantes aos de 2008 e 2009 (Figura 2). Porém tais investimentos de 2014 estão, em boa parte, relacionados a ações na área da saúde, novamente reproduzindo a tendência de "retorno" a essa área. Ainda, no que tange aos investimentos da $\mathrm{SDH}$ nesse ano, o crescimento observado é pouco significativo se comparado ao crescimento total do orçamento da SDH estipulado pelas LOA.

\section{Figura 2}

Volume de recursos transferidos por meio de ações governamentais exclusivamente relacionadas a pessoas LGBT e suas demandas e a organizações da ABGLT por ano (2004-2014)

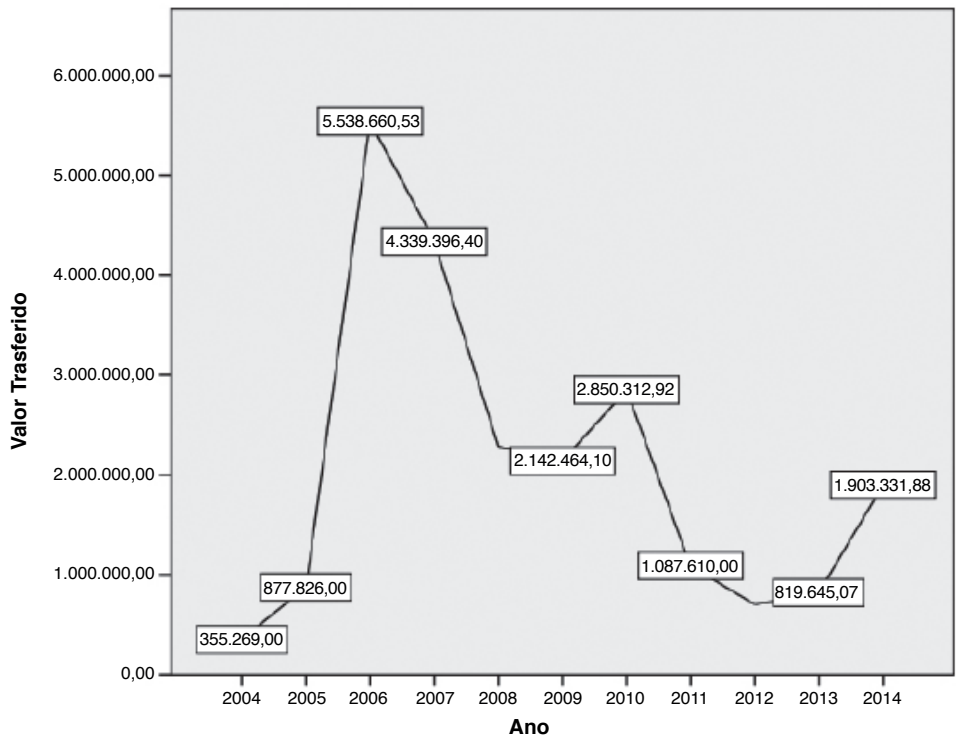

Fonte: autoria própria com dados do Portal da Transparência. 
Analisando em conjunto os dados apresentados, é possível descrever a seguinte dinâmica. No primeiro Governo Lula, o BSH começou a inserir o tema da homofobia na agenda governamental e iniciativas começaram a ser desenvolvidas, sendo realizados altos investimentos nessa área no final desse governo. No segundo Governo Lula, apesar do declínio na transferência de recursos, foram realizadas ações que possibilitaram maior acesso dos ativistas aos mecanismos institucionais de participação, tais como conselhos e conferências de políticas públicas. No início do primeiro Governo Dilma, as iniciativas continuaram a ser desenvolvidas, porém, ao final desse governo, estavam praticamente limitadas a encontros e seminários, em sua maioria na área da saúde. Nesse governo, ocorreu também um forte declínio no investimento em ações voltadas a pessoas LGBT, dificultando a efetivação das iniciativas do governo, principalmente, a partir de 2011.

\section{Frente Parlamentar Evangélica nas coalizões dos Governos Federais do PT}

Por que, apesar da manutenção do perfil ideológico da chefia do Executivo Federal e das redes do movimento nos órgãos do Governo Federal, os investimentos em ações que respondem às demandas do movimento LGBT caíram a partir do primeiro Governo Dilma? Esta seção visa identificar mudanças nas coalizões de governo entre 2003 e 2014 que podem ter impactado tal processo. Os dados aqui mobilizados se referem à passagem do segundo Governo Lula para o primeiro Governo Dilma, momento em que maiores mudanças nos resultados políticos desse movimento ocorreram.

Os dados sobre a presença numérica de deputados da FPE nas coalizões dos governos do PT indicam que houve um aumento brusco na presença de membros dessa frente nas coalizões entre o segundo Governo Lula e o primeiro Governo Dilma. Esse aumento pode ser explicado por uma 
retomada do crescimento da frente, que diminuíra seu tamanho na passagem do primeiro para o segundo Governo Lula devido ao envolvimento de alguns de seus membros em um caso de corrupção (Dantas, 2011; Duarte, 2011; Gonçalves, 2016). De forma geral, a presença da FPE na Câmara dos Deputados mais do que dobrou na passagem do segundo Governo Lula para o primeiro Governo Dilma (de 33 para 70 parlamentares).

Dentro das coalizões de governo, a proporção de deputados da FPE cresceu constantemente, indo de 6\% (18 deputados) na primeira coalizão do segundo Governo Lula para 11\% (34 deputados) na última coalizão do primeiro Governo Dilma (Figura 3). Essa mudança pode ser relacionada às alianças formadas pelo PT com o setor evangélico ao longo das eleições de 2010, nas quais temas como o aborto e a união civil entre pessoas do mesmo sexo foram mobilizados pelos adversários da futura presidenta. Tal processo 238 culminou em um posicionamento público de Dilma, que afirmou que, caso eleita, não tomaria medidas relacionadas a esses temas (Machado, 2012; Trevisan, 2013).

Figura 3

Composição das coalizões do segundo Governo Lula ao primeiro Governo Dilma na Câmara dos Deputados de acordo com pertencimento das deputadas e dos deputados à FPE

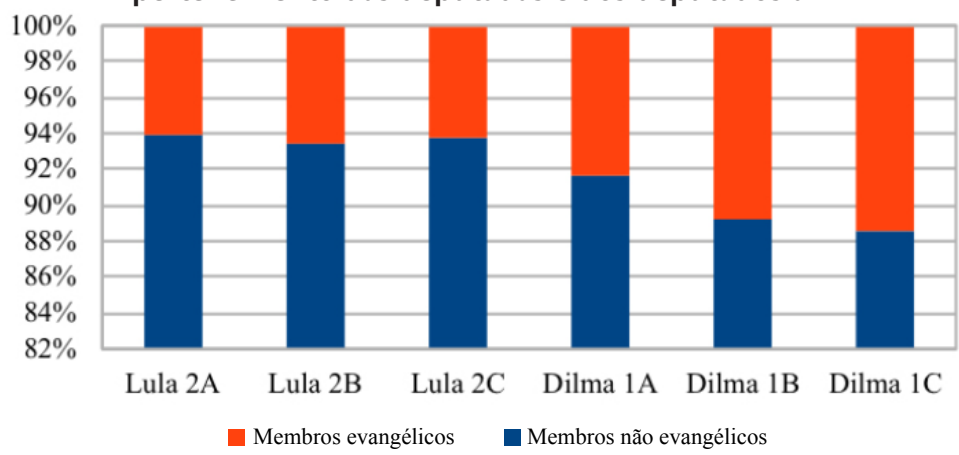

Fonte: autoria própria com dados do Portal da Câmara dos Deputados. 
A dependência do governo em relação aos deputados da FPE, no entanto, variou de forma menos estável nesse período. Isso ocorreu na medida em que o primeiro Governo Dilma contou com uma coalizão maior que a do governo anterior. Assim, mesmo que proporcionalmente houvesse maior número de deputados da FPE nas coalizões desse governo, é possível argumentar que, até 2013, a chefia do Executivo não dependia desses deputados de forma muito mais significativa que o governo anterior para atingir maioria em votações no plenário (Figura 4). Esses dados ambíguos indicam que apenas a presença numérica de deputados da FPE nas coalizões de governo é insuficiente para compreender o fenômeno aqui investigado.

Figura 4

Número absoluto de parlamentares membros das coalizões de governos do segundo Governo Lula e do primeiro Governo Dilma pertencentes à FPE (Câmara dos Deputados)

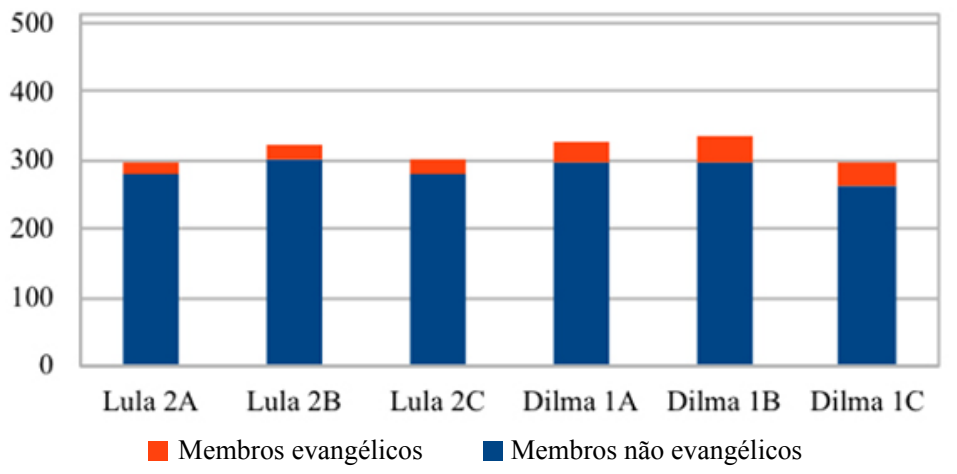

Fonte: autoria própria com dados do Portal da Câmara dos Deputados.

Isso ocorre pois grupos de parlamentares não têm poder apenas em decorrência de seu número na Câmara dos Deputados. Diferentes posições dentro da estrutura legislativa conferem diferentes poderes aos congressistas. Determinadas posições podem ser especialmente 
importantes para influenciar determinados tipos de política. Dados da escala de poder posicional de deputados da FPE sobre políticas públicas voltadas à população LGBT indicam que, na passagem do segundo Governo Lula para o primeiro Governo Dilma, deputados dessa frente se tornaram não apenas numericamente mais importantes, mas também passaram a ocupar posições mais estratégicas em suas iniciativas de oposição ao movimento LGBT. De forma geral, a soma do escore de influência de todos os deputados da FPE passou de 128 para 336 pontos do segundo Governo Lula para o primeiro Governo Dilma e a média do escore de cada deputado passou de 3,8 para 4,8.

Analisando-se apenas os deputados federais pertencentes às coalizões de governo formadas nesse período, um movimento semelhante pode ser observado (Figuras 5 e 6). Nota-se leve crescimento na soma e na média do escore dessa escala ao longo do segundo Governo Lula, com 240 pequena queda na soma desse escore na última coalizão desse governo. Os números crescem em grande medida na passagem para o primeiro Governo Dilma. A soma do escore tem grande aumento nas duas primeiras coalizões desse governo, com leve queda na terceira. Já a média desse cresce constantemente ao longo do primeiro Governo Dilma. Tais dados indicam que a composição das coalizões de governo incluiu deputadas da FPE com maior poder posicional para se opor a políticas públicas destinadas a pessoas LGBT a partir do primeiro Governo Dilma e, especialmente, a partir de sua segunda coalizão, iniciada em março de 2012. 


\section{Figura 5}

Soma do escore ponderado da escala de poder posicional dos deputados federais da FPE pertencentes às coalizões de governo do segundo Governo Lula e do primeiro Governo Dilma em questões LGBT ( $\mathrm{n}=$ número de deputados)

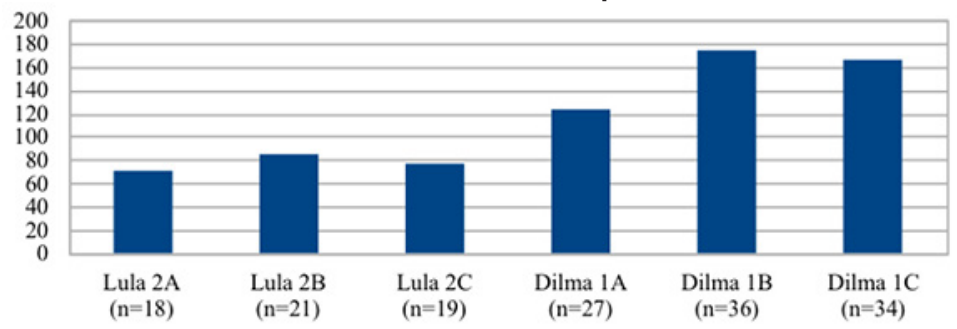

- Soma Escore Ponderado

Fonte: autoria própria, com dados do Portal da Câmara dos Deputados.

Figura 6

Média do escore ponderado da escala de poder posicional dos deputados federais da FPE pertencentes às coalizões de governo do segundo Governo Lula e do primeiro Governo Dilma em questões LGBT ( $\mathrm{n}$ = número de deputados)

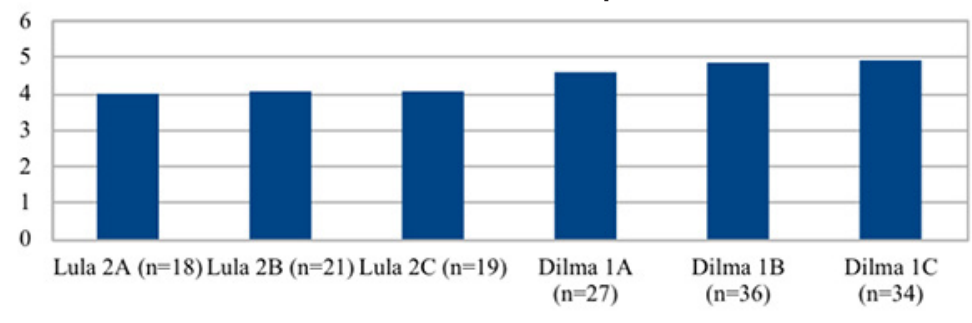

- Média Escore Ponderado

Fonte: autoria própria, com dados do Portal da Câmara dos Deputados.

Os dados sobre o poder posicional de deputados da FPE em políticas públicas voltadas a pessoas LGBT dentro das coalizões de governo vão ao encontro dos dados referentes à diminuição nos investimentos federais no combate à homofobia ao longo do primeiro Governo Dilma. Maior investimento ocorreu no segundo Governo Lula, quando a influência desses deputados era mais limitada. Com o crescimento da influência da FPE no primeiro Governo Dilma, principalmente a partir 
de 2012, o Governo Federal parece ter se adaptado às pressões de seus aliados conservadores, modificando sua postura em relação às políticas públicas voltadas a pessoas LGBT.

Poderia se argumentar, no entanto, que o perfil das coalizões e a ocupação de posições estratégicas dentro do Congresso Nacional por parte de deputados contrários ao movimento LGBT não influenciam a chefia do Executivo caso esse mantenha controle sobre sua coalizão. Isso, porém, não ocorreu no período analisado. Como é possível observar na Figura 7, o primeiro Governo Dilma parece ter perdido o controle sobre sua coalizão de governo, principalmente após o ano de 2013 - isto é um fenômeno a ser investigado. Não parece coincidência, no entanto, que tal processo se intensifique após os protestos ocorridos em junho de 2013, que impactaram de forma significativa a popularidade da presidenta ${ }^{12}$.

\section{Figura 7}

Disciplina legislativa das coalizões de governo por coalizão entre 2007 e 2014 ( $\mathrm{n}$ = número de votações nominais em plenário) (Câmara dos Deputados)

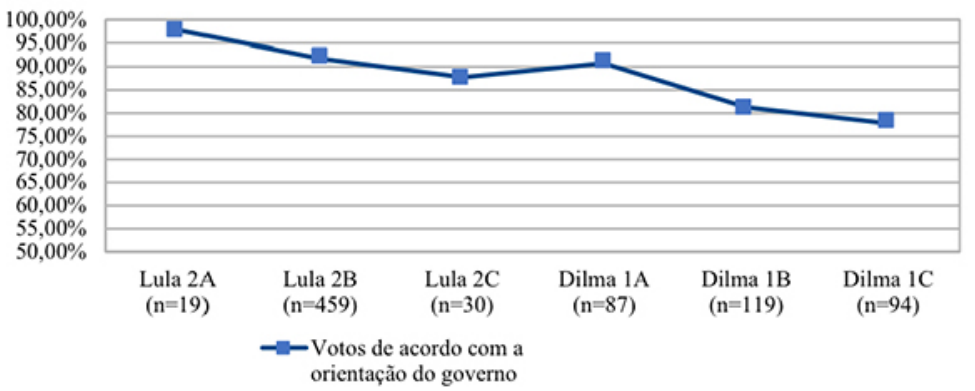

Fonte: autoria própria com dados do Estadão Dados

12 De acordo com dados do Datafolha, do período entre 6 e 7 de junho de 2013 para o período entre 27 e 28 de junho desse mesmo ano, a aprovação positiva da presidenta (ótimo ou bom) caiu bruscamente de $57 \%$ para 30\% (datafolha.folha.uol.com.br/opiniaopublica/2013/06/1303659-aprovacao-a-governo-dilma-rousseff-cai-27-pontos-em-tres-semanas.shtml - acesso em fevereiro de 2018). Sua avaliação positiva se recuperou para $42 \%$ no final de seu primeiro governo, no entanto sem atingir níveis próximos aos observados no início desse governo, no qual sua aprovação chegou a $65 \%$ (datafolha.folha.uol.com.br/opiniaopublica/2014/12/1559419-responsabilzada-por-petrobras-pela-maioria-dilma-tem-avaliacao-estavel.shtml - acesso em fevereiro de 2018). 
Em conjunto, os dados sobre as coalizões dos governos do PT indicam o seguinte processo. Entre o segundo Governo Lula e o primeiro Governo Dilma, as coalizões de governo se tornaram cada vez mais conservadoras em relação às demandas do movimento LGBT, sendo a mudança mais intensa observada justamente na troca de governos. A FPE, aberta opositora do movimento LGBT, cresceu dentro das coalizões de governo não apenas em número, mas, principalmente, em poder de influência sobre políticas públicas voltadas a pessoas LGBT. Assim, o primeiro Governo Dilma foi marcado pela negociação de compromissos entre a chefia do Executivo e sua coalizão de governo crescentemente conservadora, nas quais as ações voltadas à população LGBT perderam força nos subsistemas de políticas públicas.

\section{Considerações finais}

No dia 17 de abril de 2016, as consequências do crescimento das forças conservadoras em uma coalizão de governo fora de controle se tornaram claras. Naquele dia, deputados que, semanas antes, faziam parte da coalizão do segundo Governo Dilma votaram a favor da admissibilidade do processo de impeachment da presidenta, justificando seus votos principalmente pela defesa de "Deus" e da "família"13. O impeachment/golpe sobre a presidenta Dilma Rousseff parece ter sido a consequência definitiva do crescimento do conservadorismo na sua coalizão e da incapacidade da chefia do Executivo de conciliar seus interesses aos interesses dessas forças emergentes.

Neste artigo, argumentei que o gerenciamento dos interesses dos membros das coalizões de governo também tem consequências menos visíveis que essa para movimentos sociais no Brasil. A heterogeneidade das coalizões de governo

\footnotetext{
13 Ver matéria disponível em: <https://brasil.elpais.com/brasil/2016/04/18/politica/1460935957_433496.html>. Acesso em: fev. 2018.
} 
brasileiras obriga a chefia do Executivo a ceder espaços aos seus aliados dessemelhantes em determinados subsistemas de políticas públicas, muitas vezes contrariando os interesses dos movimentos sociais e das burocracias que sejam próximas ao partido que ocupa a presidência. Dessa forma, enquanto parte da literatura pensou governos de forma homogênea e outra parte da literatura subestimou a importância da chefia dos governos frente ao foco em sua heterogeneidade, argumentei, neste artigo, que, devido ao desenho das instituições políticas brasileiras, oportunidades políticas se abrem e se fecham para movimentos sociais no Brasil de acordo com o gerenciamento que governos fazem de sua heterogeneidade, gerenciando os interesses dos membros de suas coalizões ao agir sobre os conflitos internos aos subsistemas de políticas públicas.

No caso do movimento LGBT e do combate à homofobia em governos federais do PT entre 2003 e 2014, os dados aqui apresentados indicam que, apesar da manutenção do perfil 244 ideológico da chefia do Executivo e das redes do movimento LGBT dentro dos órgãos do Governo Federal, houve um decréscimo na obtenção de resultados políticos positivos para esse movimento nesse período. Esses dados indicam, ainda, que essa diminuição foi concomitante ao aumento da força da FPE nas coalizões de governo. Dessa forma, a chefia do Executivo teve uma motivação para agir sobre seus subsistemas de forma a obstaculizar a ação de coalizões de defesa do combate à homofobia: a manutenção da fidelidade de sua coalizão.

Pela natureza dos dados aqui expostos, no entanto, não é possível mapear se e por quais formas essa intervenção ocorreu, sendo necessárias outras evidências empíricas. Porém, caso as evidências qualitativas reforcem o argumento aqui formulado, as conclusões dessa pesquisa empírica indicam a necessidade do desenvolvimento de uma agenda de pesquisa acerca de movimentos sociais, oportunidades políticas e relações entre Poder Legislativo e Executivo no Brasil. Sugiro algumas hipóteses nesse sentido. 
1) Quando movimentos sociais veem na chefia do Executivo um aliado e têm influência sobre os subsistemas de políticas públicas que lhes interessam, conquistarão resultados políticos positivos de forma regular apenas se, na coalizão de governo, seus opositores não forem numerosos ou se eles tiverem pouco poder de barganha sobre a chefia do Executivo.

2)Já quando movimentos sociais veem na chefia do Executivo um adversário, ativistas podem reverter (ainda que parcialmente) o quadro negativo se contarem com aliados numerosos e poderosos nas coalizões de governo, especialmente em momentos em que a chefia do Executivo encontra-se fragilizada.

3) O gerenciamento das coalizões deve afetar mais fortemente a abertura e o fechamento de oportunidades para movimentos sociais obterem resultados políticos positivos quando seus temas de interesse encontram oposição forte no Congresso Nacional. Caso contrário, o controle da chefia do Executivo por um aliado e a influência sobre os subsistemas de políticas públicas de interesse do movimento devem bastar para garantir resultados políticos positivos.

4) Processos eleitorais são momentos críticos para a mudança nesses quadros. Neles, são definidos os pesos numéricos dos aliados e dos adversários dos movimentos dentro do Congresso Nacional. Ainda, em troca do apoio de partidos e de grupos políticos que tenham bases ou outros recursos importantes em processos eleitorais, partidos que lançam candidaturas para chefia do Executivo fazem acordos sobre a formação do gabinete e sobre as políticas públicas que serão defendidas pelo governo. 
Este trabalho também tem consequências práticas e estratégicas importantes para ativistas de movimentos sociais. Os modelos teóricos revisados já haviam demonstrado a importância de aliados na chefia do Executivo e de "burocratas ativistas" nos subsistemas de políticas públicas para a obtenção de resultados políticos positivos. Sugiro que grande atenção deve ser dada pelos ativistas também a táticas que garantam que seus aliados no Poder Legislativo sejam numerosos e influentes. "Legisladores e assessores ativistas" podem não apenas garantir a aprovação de leis de interesse do movimento, mas também assegurar que aliados no Poder Executivo governem sem abrir mão das políticas públicas defendidas pelos ativistas. Assim, os resultados desse estudo indicam que as táticas eleitorais legislativas e a ocupação de cargos de assessoria parlamentar são centrais para as estratégias dos movimentos sociais no Brasil, em especial para aqueles que encontram fortes opositores no 246 Congresso Nacional.

\section{Matheus Mazzilli Pereira}

é doutor em Sociologia pela Universidade Federal do Rio Grande do Sul (UFRGS), com período sanduíche na University of California, Irvine. Bacharel em Ciências Sociais e mestre em Sociologia pela mesma instituição de ensino também pela UfRGS. Membro do Grupo de Pesquisa Associativismo, Contestação e Engajamento (GPACE/ UFRGS).

\section{Bibliografia}

ABERS, Rebecca. 1998. Do clientelismo à cooperação: governos locais, políticas participativas e organização da sociedade civil em Porto Alegre. Cadernos IPPUR, v. 12, n. 1, pp. 47-78.

2015. Ativismo na burocracia? O médio escalão do Programa

Bolsa Verde”. In: CAVALCANTE, Pedro Luiz Costa; LOTTA, Gabriela Spanguero (orgs.). Burocracia de médio escalão: perfil, trajetória e atuação. Brasília: Enap, pp. 143-175. 
ABERS, Rebecca; SERAFIM, Lizandra; TATAGIBA, Luciana. 2014.

Repertórios de interação Estado-sociedade em um Estado heterogêneo: a experiência na Era Lula. Dados, v. 57, n. 2, pp. 325-357.

ABERS, Rebecca; VON BÜLLOW, Marisa. 2011. Movimentos sociais na teoria e na prática: como estudar o ativismo através da fronteira entre Estado e sociedade? Sociologias, v. 13, n. 28, pp. 52-84.

ABRANCHES, Sérgio Henrique Hudson de. 1988. Presidencialismo de coalizão: o dilema institucional brasileiro. Dados, v. 31, n. 1, pp. 5-34. AGUIÃO, Silvia. 2014. Fazer-se no "Estado": uma etnografia sobre o processo de constituição dos "LGBT" como sujeitos de direito no Brasil contemporâneo. 318f. Tese de Doutorado em Ciências Sociais. Campinas: Unicamp. AGUIÃO, Silvia; VIANNA, Adriana; GUTTERRES, Anelise. 2014. Limites, espaços e estratégias de participação de movimentos LGBT nas políticas governamentais. In: LOPES, José Sérgio Leite; HEREDIA, Beatriz Maria Alasia (orgs.). Movimentos sociais e esfera pública: o mundo da participação. Rio de Janeiro: CBAE, pp. 239-269.

ALBUQUERQUE, Maria do Carmo Alves. 2015. O movimento pelos direitos da criança e do adolescente e o controle social sobre a política socioeducativa: repertórios de interação socioestatal. Política $\mathcal{E} \sigma$ Sociedade, v. 14, n. 29, pp. 31-66.

ALMEIDA, Paul D. 2003. Opportunity organizations and threat induced contention: protest waves in authoritarian settings. American Journal of Sociology, v. 109, n. 2, pp. 345-400.

AMENTA, Edwin; CAREN, Neil; STOBAUGH, James E. 2012. Political reform and the historical trajectories of U.S. social movements in the twentieth century. Social Forces, v. 90, n. 4, pp. 1073-1100.

AMENTA, Edwin; YOUNG, Michael P. 1999. Making an impact: conceptual and methodological implications of collective goods criterion. In: GIUGNI, Marco; McADAM, Doug; TILLY, Charles (orgs.). How Social Movements Matter. Minneapolis: University of Minnesota Press, pp. 22-41.

ARAÚJO, Victor Augusto. 2016. Mecanismos de alinhamento de preferências em governos multipartidários: controle de políticas públicas no presidencialismo brasileiro. Dissertação de Mestrado em Ciência Política. São Paulo: Universidade de São Paulo.

AVRITZER, Leonardo. 2003. O Orçamento Participativo e a teoria democrática: um balanço crítico. In: AVRITZER, Leonardo; NAVARRO, Zander (orgs.). A inovação democrática no Brasil: o orçamento participativo. São Paulo: Cortez, pp. 13-60. 
BANASZAK, Lee Ann 2005. Inside and outside the State: movement insider status, tactics, and public policy achievements. In: MEYER, David S.; JENNESS, Valerie; INGRAM, Helen M. (eds.). Routing the Opposition: social movements, public policy and democracy. Minneapolis: University of Minnesota Press, pp. 149-176.

CARLOS, Euzeneia. 2015. Movimentos sociais e instituições participativas - efeitos do engajamento institucional nos padrões de ação coletiva. Revista Brasileira de Ciências Sociais, v. 30, n. 88, pp. 83-99.

CARLOS, Euzeneia; DOWBOR, Monika; ALBUQUERQUE, Maria do Carmo Alves. 2016. Movimentos sociais e seus efeitos nas políticas públicas: proposições analíticas e desafios metodológicos. Paper apresentado no $40^{\circ}$ Encontro Anual da ANPOCS, Caxambu, 24 a 28 de outubro.

CARRARA, Sérgio. 2010. Políticas e direitos sexuais no Brasil contemporâneo. Bagoas, n. 5, pp. 131-147.

CHEIBUB, José Antonio; PRZEWORSKI, Adam; SAIEGH, Sebastian. 2002. Governos de coalizão nas democracias presidencialistas e parlamentaristas. Dados, v. 45, n. 2, pp. 187-218.

CORADINI, Odaci Luiz 2010. Frentes parlamentares, representação de interesses e alinhamentos políticos. Revista de Sociologia e Política, v. 18, 248 n. 36, pp. 241-256.

DANTAS, Bruna Suruagy do Amaral. 2011. Religião e política: ideologia e ação da "bancada evangélica" na Câmara Federal. 350f. Tese de Doutorado em Psicologia. São Paulo: Pontifícia Universidade Católica de São Paulo. DIAP. 2006. Radiografia do Novo Congresso - Legislatura 2007-2011 [Série Estudos Políticos]. Brasília: Departamento Intersindical de Assessoria Parlamentar. . 2010. Radiografia do Novo Congresso - Legislatura 2011/2015 [Série Estudos Políticos]. Brasília: Departamento Intersindical de Assessoria Parlamentar.

DUARTE, Tatiane dos Santos. 2011. "A casa dos ímpios se desfará, mas a tenda dos retos florescerá”: a participação da Frente Parlamentar Evangélica no legislativo brasileiro. 229f. Dissertação de Mestrado em Antropologia Social. Brasília: Universidade de Brasília.

FACCHINI, Regina. 2003. Movimento homossexual no Brasil: recompondo um histórico. Cadernos AEL, v. 10, n. 18/19, pp. 81-125. 2009. Entre compassos e descompassos: um olhar para o "campo" e para a "arena” do movimento LGBT brasileiro. Bagoas, n. 4, pp. 131-158.

FERNANDES, Felipe Bruno Martins. 2012. Por uma genealogia do conceito de homofobia no Brasil: da luta política a um campo de governança. Passages de Paris, v. 7, pp. 97-104. 
FERREIRA, Daniela Damiati; LOTTA, Gabriela Spanghero. 2016.

Burocratas: atores entre as fronteiras do Estado e da sociedade. Paper apresentado no $40^{\circ}$ Encontro Anual da ANPOCS, Caxambu, 24 a 28 de outubro.

FIGUEIREDO, Argelina Cheibub. 2012. Coalizões governamentais na democracia brasileira. Primeiros Estudos, v. 3, pp. 159-196.

FIGUEIREDO, Argelina Cheibub; LIMONGI, Fernando. 2000.

Presidential power, legislative organization, and party behavior in Brazil. Comparative Politics, v. 32, n. 2, pp. 151-170.

2001. Executivo e Legislativo na nova ordem constitucional. 2. ed. Rio de Janeiro: Editora FGV.

FREITAS, Andréa. 2016. O presidencialismo da coalizão. Rio de Janeiro: Fundação Konrad Adenauer.

FROEMMING, Cecilia Nunes; IRINEU, Bruna Andrade; NAVAS, Kleber. 2010. Gênero e sexualidade na pauta das políticas públicas no Brasil. Revista de Políticas Públicas, número especial, pp. 161-172.

GAMSON, William A.; MEYER, David. S. 1996. Framing Political Opportunity. In: McADAM, Doug.; McCARTHY, John D.; ZALD, Mayer N. (orgs.). Comparative perspectives on social movements. Cambridge: Cambridge University Press, pp. 275-290.

GIUGNI, Marco G. 1998. Was it worth the effort? The outcomes and consequences of social movements. Annual Review of Sociology, v. 24, pp. 371-393.

GIUGNI, Marco; McADAM, Doug; TILLY, Charles (orgs.). 1999. How social movements matter. Minneapolis: University of Minnesota Press.

GOLDSTONE, Jack. 2003. Bridging institutionalized and noninstitutional politics. States, Parties and Social Movements. Cambridge: Cambridge University Press, 2003, pp. 1-24.

GONÇALVES, Rafael Bruno. 2016. O discurso religioso na política e a política no discurso religioso: uma análise da atuação da Frente Parlamentar Evangélica na Câmara dos Deputados (2003-2014). 262 f. Tese de Doutorado em Sociologia. Rio de Janeiro: Universidade do Estado do Rio de Janeiro.

GRANGEIRO, Alexandre; SILVA, Lindinalva Laurindo da; TEIXEIRA, Paulo Roberto. 2009. Resposta à aids no Brasil: contribuições dos movimentos sociais e da reforma sanitária. Revista Panamericana de Salud Pública, v. 26, n. 1, pp. 87-94.

HIROI, Taeko; RENNÓ, Lucio. 2014. Obstrução e processo decisório na Câmara dos Deputados: 1990 a 2010. Texto para Discussão IPEA, v. 1957, pp. 7-39. 
IRINEU, Bruna Andrade. 2014. 10 anos do Programa Brasil Sem Homofobia: notas críticas. Temporais, v. 14, n. 28, pp. 193-220.

KATZENSTEIN, Mary Fainsod. 1990. Feminism within American institutions: unobtrusive mobilization in the 1980s. Signs, v. 16, n. 1, pp. 27-54.

LUCHMANN, Lígia Helena Hahn. 2002. Possibilidades e limites da democracia deliberativa: a experiência do Orçamento Participativo de Porto Alegre. 225f. Tese de Doutorado em Ciências Socias. Campinas: Unicamp.

MACHADO, Frederico Viana; RODRIGUES, Cristiano Santos. 2015. Movimentos negro e LGBT no Governo Lula: desafios da institucionalização segmentada. In: MACHADO, Frederico Viana; MASSOLA, Gustavo Martineli; RIBEIRO, Maria Auxiliadora Teixeira (orgs.). Estado, ambiente e movimentos sociais. Florianópolis: Edições do Bosque, pp. 22-45.

MACHADO, Maria das Dores Campos. 2012. Aborto e ativismo religioso nas eleições de 2010. Revista Brasileira de Ciência Política, n. 7, pp. 25-54.

McADAM, Doug. 1986. Political process and the development of black insurgency 1930-1970. 2. ed. Chicago: The University of Chicago Press. 1996. Conceptual origins, current problems, future directions. In: McADAM, Doug; McCARTHY, John D.; ZALD, Mayer N. (orgs.). Comparative perspectives on social movements. Cambridge: Cambridge University Press, 1996, pp.23-40.

McADAM, Doug; TARROW, Sidney. 2011. Movimentos sociais e eleições: por uma compreensão mais ampla do contexto político da contestação. Sociologias, v. 13, n. 28, pp. 18-51.

MELLO, Luiz; AVELAR, Rezende Bruno de; MAROJA, Daniela. 2012. Por onde andam as políticas públicas para a População LGBT no Brasil. Sociedade e Estado, v. 27, n. 2, pp. 289-312.

MEYER, David S. 1993a. Peace protest and policy: explaining the rise and decline of antinuclear movements in postwar America. Policy Studies Journal, v. 21, n. 1, pp. 35-51. 1993b. Institutionalizing dissent: The United States structure of political opportunity and the end of the Nuclear Freeze movement. Sociological Forum, v. 8, n. 2, pp. 157-179.

MEYER, David S.; MINKOFF, Debra C. 2004. Conceptualizing Political Opportunity. Social Forces, v. 82, n. 4, pp. 1457-1492.

MÜLLER, Gustavo. 2005. Comissões e partidos políticos na Câmara dos Deputados: um estudo sobre os padrões partidários de recrutamento para as comissões permanentes. Dados, v. 48, n. 2, pp. 371-394. 
PETTINICCHIO, David. 2012. Institutional activism: reconsidering the insider/outsider dichotomy. Sociology Compass, v. 6, n. 6, pp. 499-510. RAMOS, Sílvia. 2004. O papel das ONGs na construção de políticas de saúde: a Aids, a saúde da mulher e a saúde mental. Ciência Saúde Coletiva, v. 9, n. 4, pp. 1067-1078.

RAMOS, Sílvia; CARRARA, Sérgio. 2006. A constituição da problemática da violência contra homossexuais: a articulação entre ativismo e academia na elaboração de políticas públicas. Physis, v. 16, n. 2, pp. 185-205.

SABATIER, Paul A.; WEIBLE, Christopher M. 2007. The Advocacy Coalition Framework: innovations and clarifications. In: SABATIER, Paul A. (org.) Theories of the Policy Process. Boulder: Westview Press, pp. 189-220.

SCHMITT, Claudia Job; SILVA, Marcelo Kunrath. 2016. Das relações Estado/mercado/sociedade civil aos campos de ação estratégica: uma análise das organizações de movimentos sociais na implementação do Programa de Aquisição de Alimentos. In: MARQUES, Flávia Charão; CONTERATO, Marcelo Antônio; SCHNEIDER, Sergio (orgs.). Construção de mercados e agricultura familiar: desafios para o desenvolvimento rural. Porto Alegre: Editora da UFRGS, pp.381-408.

SILVA, Marcelo Kunrath. 2003. A expansão do Orçamento Participativo na Região Metropolitana de Porto Alegre: condicionantes e resultados. In: AVRITZER, Leonardo; NAVARRO, Zander. (orgs.). A inovação democrática no Brasil: o orçamento participativo. São Paulo: Cortez, pp. 157-185.

2015. Atores, espaços e repertórios: a atuação de movimentos sociais através das fronteiras da sociedade civil e do Estado. In: SCHERER-WARREN, Ilse; LÜCHMANN, Ligia Helena H. (orgs.). Movimentos sociais e engajamento político: trajetórias e tendências analíticas. Florianópolis: Editora UFSC, pp. 133-160.

SILVA, Marcelo Kunrath; OLIVEIRA, Gerson de Lima. 2011. A face oculta(da) dos movimentos sociais: trânsito institucional e intersecção Estado-movimento - uma análise do movimento de economia solidária no Rio Grande do Sul. Sociologias, v. 13, n. 28, pp. 86-124.

SILVA, Vitor Augusto Araújo. 2012. Grupos suprapartidários no Congresso brasileiro: uma análise da Frente Parlamentar Evangélica. Revista Três Pontos, v. 9, n. 2, pp. 27-36.

TARROW, Sidney. 2009. O poder em movimento: movimentos sociais e confronto político. Petrópolis: Vozes. 
TATAGIBA, Luciana. 2010. Desafios da relação entre movimentos sociais e instituições políticas: o caso do movimento de moradia da cidade de São Paulo - primeiras reflexões. Colombia Internacional, v. 71, pp. 63-83.

TATAGIBA, Luciana; TEIXEIRA, Ana Claudia Chaves. 2016. Efeitos combinados dos movimentos de moradia sobre os programas habitacionais autogestionários. Revista de Sociologia e Política, v. 24, n. 58, pp. 85-102.

TEIXEIRA, Ana Claudia Chaves. 2003. O OP em pequenos municípios rurais: contextos, condições de implementação e formatos de experiência. In: AVRITZER, Leonardo; NAVARRO, Zander. (orgs.). A inovação democrática no Brasil: o orçamento participativo. São Paulo: Cortez, pp. 189-216.

TILLY, Charles. 1997. Parliamentarization of popular contention in Great Britain, 1758-1834. Theory and Society, v.26, n.2/3, pp.245-273.

TREVISAN, Janine. 2013. A Frente Parlamentar Evangélica: força política no Estado laico brasileiro. Numen, v. 16, n. 1, pp. 581-609.

VAN DYKE, Nella. 2003. Protest cycles and party politics: the effects of elite allies and antagonists on student protests in the United States, 1930-1990. In: GOLDSTONE, Jack A. (org.). States, parties and social movements. Cambridge: Cambridge University Press, pp. 226-245.

252 WAMPLER, Brian. 2003. Orçamento Participativo: uma explicação para as amplas variações nos resultados. In: AVRITZER, Leonardo; NAVARRO, Zander. (orgs.). A inovação democrática no Brasil: o orçamento participativo. São Paulo: Cortez, pp. 61-86. 


\section{OPORTUNIDADES POLÍTICAS EM UM PRESIDENCIALISMO DE COALIZÃO}

MATHEUS MAZZILLI PEREIRA

Resumo: Ao longo dos governos federais do PT, o movimento LGBT conquistou importantes resultados políticos que, porém, variaram negativamente a partir de 2011. Analisando-se o impacto de oportunidades políticas sobre os resultados de movimentos sociais, como explicar tal variação se, ao longo desse período, um mesmo partido chefiou o Poder Executivo e as redes desse movimento se mantiveram ativas na burocracia estatal? Sugiro, neste artigo, que oportunidades políticas se abrem e se fecham no Brasil pelo gerenciamento da chefia do Executivo sobre as preferências de sua burocracia e de seus aliados de coalizão de governo. Os dados aqui apresentados indicam que variações nos investimentos do Governo Federal no combate à homofobia foram concomitantes ao crescimento da Frente Parlamentar Evangélica nas coalizões de governo, sugerindo que o fortalecimento de grupos parlamentares conservadores afetou os resultados do movimento LGBT.

Palavras-chave: oportunidades políticas; presidencialismo de coalizão; movimento LGBT; Frente Parlamentar Evangélica.

\section{POLITICAL OPPORTUNITIES IN A COALITION PRESIDENTIALISM}

Abstract: During the Partido dos Trabalhadores' federal administrations, the LGBT movement had important political outcomes that, nevertheless, decreased since 2011. Analyzing the impact of political opportunities over social movement outcomes, how can one explain this variation if only one party was chief of the Executive branch during this period and the LGBT movement sustained its networks in the state bureaucracy? In this paper, I 
suggest that the management of the Chief Executive over its bureaucracies' and government coalition allies' preferences opens and closes political opportunities in Brazil. The data presented here indicates that federal investments against homophobia varied along with the growth of the Frente Parlamentar Evangélica in the government coalitions, suggesting that the fortification of conservative parliamentary groups affected the outcomes of the LGBT movement.

Keywords: political opportunities; coalition presidentialism; LGBT movement; Frente Parlamentar Evangélica.

Recebido: 05/06/18

Aprovado: 23/10/18 